\title{
Aspirin delays mesothelioma growth by inhibiting HMGB1-mediated tumor progression
}

\author{
H Yang ${ }^{*, 1}$, L Pellegrini ${ }^{1}$, A Napolitano ${ }^{1,2}$, C Giorgi ${ }^{3}$, S Jube ${ }^{1}$, A Preti ${ }^{4}$, CJ Jennings ${ }^{1}$, F De Marchis ${ }^{4}$, EG Flores ${ }^{1}$, D Larson ${ }^{1}$, I Pagano ${ }^{1}$, \\ M Tanji ${ }^{1}$, A Powers ${ }^{1}$, S Kanodia ${ }^{5}$, G Gaudino ${ }^{1}$, S Pastorino ${ }^{1}$, HI Pass ${ }^{6}$, P Pinton ${ }^{3}$, ME Bianchi ${ }^{4}$ and M Carbone ${ }^{\star, 1}$
}

High-mobility group box 1 (HMGB1) is an inflammatory molecule that has a critical role in the initiation and progression of malignant mesothelioma (MM). Aspirin (acetylsalicylic acid, ASA) is the most widely used nonsteroidal anti-inflammatory drug that reduces the incidence, metastatic potential and mortality of many inflammation-induced cancers. We hypothesized that ASA may exert anticancer properties in MM by abrogating the carcinogenic effects of HMGB1. Using HMGB1-secreting and -non-secreting human MM cell lines, we determined whether aspirin inhibited the hallmarks of HMGB1-induced MM cell growth in vitro and in vivo. Our data demonstrated that ASA and its metabolite, salicylic acid (SA), inhibit motility, migration, invasion and anchorageindependent colony formation of MM cells via a novel HMGB1-mediated mechanism. ASA/SA, at serum concentrations comparable to those achieved in humans taking therapeutic doses of aspirin, and BoxA, a specific inhibitor of HMGB1, markedly reduced MM growth in xenograft mice and significantly improved survival of treated animals. The effects of ASA and BoxA were cyclooxygenase-2 independent and were not additive, consistent with both acting via inhibition of HMGB1 activity. Our findings provide a rationale for the well documented, yet poorly understood antitumorigenic activity of aspirin, which we show proceeds via HMGB1 inhibition. Moreover, the use of BoxA appears to allow a more efficient HMGB1 targeting while eluding the known gastrointestinal side effects of ASA. Our findings are directly relevant to MM. Given the emerging importance of HMGB1 and its tumor-promoting functions in many cancer types, and of aspirin in cancer prevention and therapy, our investigation is poised to provide broadly applicable information.

Cell Death and Disease (2015) 6, e1786; doi:10.1038/cddis.2015.153; published online 11 June 2015

Malignant mesothelioma (MM) is an aggressive cancer that arises from the neoplastic transformation of mesothelial cells lining the pleural, peritoneal, and pericardial cavities. ${ }^{1}$ In the United States, 3200 individuals are diagnosed annually with MM and a similar number dies of this almost invariably fatal disease. ${ }^{1}$ Major risk factors for MM are exposure to asbestos and erionite mineral fibers and germline BAP1 mutations. ${ }^{1,2}$

We have demonstrated that high-mobility group box 1 (HMGB1), the prototypical damage-associated molecular pattern molecule that is normally present in the nucleus of cells, is a critical mediator of asbestos-induced MM (reviewed in Carbone and $\mathrm{Yang}^{3}$ ). Within the nucleus, HMGB1 is a nonhistone chromatin-binding protein that regulates nucleosome assembly and chromatin structure. ${ }^{4}$ HMGB1 is passively released by necrotic cells or actively secreted by immune and cancer cells. ${ }^{4-7}$ When in the extracellular space, HMGB1 is responsible for the initiation and perpetuation of the inflammatory response and also directly promotes MM growth. ${ }^{4,5,7}$
Our published data show that asbestos causes necrosis of primary human mesothelial cells that results in the passive release of HMGB1 into the extracellular space where it induces the secretion of TNF- $a$ and other cytokines, recruits macrophages and thus initiates inflammation. ${ }^{5}$ The prolonged biopersistence of asbestos fibers lodged in the pleura initiates a vicious cycle of chronic cell death and chronic inflammation that, over a period of many years, can lead to MM. ${ }^{5}$ As MM arises in an HMGB1-rich environment, most of the MM cells are HMGB1 growth dependent and require HMGB1 to migrate and invade nearby tissues. ${ }^{7}$ Accordingly, out of seven MM cell lines available in our lab, six actively secrete high amounts of HMGB1 and are dependent on it for growth. ${ }^{7}$ Moreover, we have demonstrated that the tumor phenotype of HMGB1-secreting human MM cells requires HMGB1 for continued growth, and that abrogation of HMGB1 function may have therapeutic efficacy. ${ }^{7}$

Although MM is the most well-characterized HMGB1related tumor model, ${ }^{7}$ the relevance of extracellular HMGB1

\footnotetext{
${ }^{1}$ University of Hawaii Cancer Center, University of Hawaii, Honolulu, HI 96813, USA; ${ }^{2}$ Department of Molecular Biosciences and Bioengineering, University of Hawaii, Honolulu, HI 96813, USA; ${ }^{3}$ Department of Morphology, Surgery and Experimental Medicine, University of Ferrara, Ferrara 44121, Italy; ${ }^{4}$ San Raffaele University and Scientific Institute, Milan 20132, Italy; ${ }^{5}$ Samuel Oschin Comprehensive Cancer Institute and Department of Biomedical Sciences, Cedars-Sinai Medical Center, Los Angeles, CA 90048, USA and ${ }^{6}$ Department of Cardiothoracic Surgery, New York Langone Medical Center, New York, NY 10016, USA

${ }^{*}$ Corresponding author: H Yang, University of Hawaii Cancer Center, University of Hawaii, 701 llalo Street, Room 439, Honolulu, HI 96813, USA. Tel: +1 808 440 4588; Fax: +1 808587 0790; E-mail: hyang@cc.hawaii.edu

or M Carbone, University of Hawaii Cancer Center, University of Hawaii, 701 llalo Street, Room 450, Honolulu, HI 96813, USA. Tel: +1 8084404596 ; Fax: +1 808 587 0790; E-mail: mcarbone@cc.hawaii.edu

Abbreviations: ASA, acetylsalicylic acid; COX, cyclooxygenase enzymes; EMT, epithelial-mesenchymal transition; fMLP, $N$-formyl-methionyl-leucyl-phenylalanine; GI, gastrointestinal; HMGB1, high-mobility group box 1; MEF, mouse embryonic fibroblast; MM, malignant mesothelioma; NSAID, nonsteroidal anti-inflammatory drug; SA, salicylic acid; SCID, severe-combined immunodeficient; TNF- $\alpha$, tumor necrosis factor- $\alpha$

Received 24.3.15; revised 04.5.15; accepted 07.5.15; Edited by G Melino
} 
to carcinogenesis has also been proposed in other inflammation-related malignancies. ${ }^{8}$ Recent data indicate that HMGB1 initiates a chain of events that promotes tumor metastasis in melanoma, ${ }^{9}$ a malignancy that shares some common molecular pathogenetic mechanisms with $\mathrm{MM}^{2}$ HMGB1 levels in blood are elevated in $\mathrm{MM}^{7,10}$ and in several other inflammation-related cancers. ${ }^{11,12}$

Acetylsalicylic acid (ASA), commonly known as aspirin, is the most widely used nonsteroidal anti-inflammatory drug (NSAID) worldwide. ${ }^{13}$ In addition to its well-known effects in reducing inflammation, and preventing platelet aggregation and related effects on cardiovascular diseases, ASA reduces the incidence, metastatic potential and mortality of colon cancer, and possibly of other solid malignancies, most of which have inflammation-mediated initiation or progression. ${ }^{14,15}$

ASA is absorbed by the stomach and upper intestine and is deacetylated to form salicylic acid (SA) in about 15-30 min. SA has a half-life of several hours in human plasma; thus, much of ASA bioactivity is attributed to SA. In humans, peak levels of SA in plasma vary between 20 and $150 \mu \mathrm{M}$ at ASA doses of $\leq 325 \mathrm{mg}$ per day and vary between 0.3 and $1.5 \mathrm{mM}$ in patients taking up to $1.5 \mathrm{~g}$ per day of ASA. ${ }^{16,17}$ These doses are hereafter collectively referred to as 'therapeutic levels' as these are the dose ranges of aspirin that are administered for different therapies to millions of people every day.

To the best of our knowledge, the possible beneficial effects of ASA in human MM have not been investigated. However, by reviewing the information collected for the Physician's Health Study, ${ }^{18}$ we found data suggesting a possible association between ASA use and reduced MM incidence. In this study, 22067 physicians were followed for 24 years with 17 reported cases of MM. An intention-to-treat analysis comparing ASA (325 mg on alternate days) and placebo treatment revealed a relative risk of 0.7 (0.3-1.9, 95\% confidence interval), indicating a $30 \%$ reduction in MM risk. The small number of MM cases resulted in insufficient power for a statistically significant analysis; however, these findings suggested that ASA might have the potential as an effective drug for MM. In the present study, we demonstrate that ASA and its metabolite, SA, exert anticancer activity against MM by inhibiting the biological effects of HMGB1 at physiologically relevant concentrations.

\section{Results}

Treatment with ASA significantly reduces MM tumor growth in vivo. To determine whether ASA influences MM growth in vivo, a xenograft model was established by injecting severe-combined immunodeficient (SCID) mice with luciferase-expressing HMGB1-secreting human MM cell line REN (REN/luc) intraperitoneally. ${ }^{7}$ ASA was given by oral gavage at the doses of $25 \mathrm{mg} / \mathrm{kg}$ per day, which according to previous studies should be equivalent to $80-110 \mathrm{mg}$ per day in humans. ${ }^{19}$ ASA treatment was initiated 4 days after injecting REN/luc cells, which is when the tumors became detectable by IVIS imaging. ASA was administered daily thereafter, until the experiment was halted because of gastrointestinal (Gl) bleeding (Figure 1a). A slope comparison test revealed that ASA treatment caused a significant suppression of MM growth compared with controls $(t(67)=4.8, P<0.0001)$ (Figure 1b). Mice receiving ASA showed a significant reduction of HMGB1 in serum (Figure 1c). We ruled out the possibility that SAHMGB1 interaction might impair measurement of HMGB1 by ELISA (Supplementary Figure S1). Therefore, the lower amount of HMGB1 in the serum of mice receiving ASA may be related to smaller tumor sizes.

The experiment was repeated with a modified protocol designed to reduce ASA side effects, such as GI bleeding. When the tumors were established and visible by IVIS (day 4 postinjection of REN/luc cells), ASA was administered by oral gavage daily for the first 2 weeks, and three times per week thereafter. Two different doses of ASA ( 25 and $50 \mathrm{mg} / \mathrm{kg}$ ) were used, which yielded slightly different peak levels of SA in plasma, with the $50 \mathrm{mg} / \mathrm{kg}$ dose of ASA providing SA for a longer duration. Specifically, these doses achieved peak levels of SA of 1 and $1.3 \mathrm{mM}$, respectively, at $30 \mathrm{~min}$ postASA administration, which decreased to 0.4 and $0.7 \mathrm{mM}$, respectively, at $2 \mathrm{~h}$ post-ASA administration (Figure $1 \mathrm{~d}$ ).

Forty-eight days from MM cell injection, the tumor growth curves (Figures 1e and f) were comparable with those observed in the previous experiment (Figures 1a and b), and showed a marked reduction in tumor growth in animals receiving ASA $(t(302)=11.2, P<0.0001$, based on a slope comparison test). As there was no evidence of Gl bleeding, the experiment could be continued past 48 days. Median survival was 76 days in the control group, 87.5 days in the ASA $25 \mathrm{mg} / \mathrm{kg}$ group and 91 days in the ASA $50 \mathrm{mg} / \mathrm{kg}$ group. The increased survival of treated animals was statistically

\footnotetext{
Figure 1 Treatment with ASA significantly reduces MM tumor growth in vivo. Fourteen SCID mice were injected intraperitoneally with $5 \times 10^{5}$ REN/luc cells. After formation of detectable tumor nodules by IVIS imaging (4 days after cells injection), mice were weighed and randomly assigned to control (gavage of vehicle solution) and treatment (gavage of $25 \mathrm{mg} / \mathrm{kg}$ per day ASA); groups of seven animals each. (a) Representative IVIS images. (b) Tumor growth curves of the two groups. Based on a slope comparison test, ASA treatment resulted in significant suppression of MM growth compared with controls $(t(67)=4.8, P<0.0001)$. (c) Female SCID mice were randomly assigned to receive ASA$(25 \mathrm{mg} / \mathrm{kg})$ or vehicle-supplemented gavage feeding. Blood was collected by cheek bleeding and serum levels of HMGB1 were measured by ELISA. ${ }^{*} P<0.05$. (d) SA plasma levels in mice receiving ASA. Fifteen female SCID mice were randomly assigned to receive ASA ( $25 \mathrm{or} 50 \mathrm{mg} / \mathrm{kg}$ ) or vehicle by gavage feeding in groups of five mice. Blood was collected by cheek bleeding at different time points ranging from 30 min to $24 \mathrm{~h}$ after feeding, and plasma levels of SA were measured with a specific ELISA. (e) Representative IVIS images at different days postinjection of REN/luc cells shows reduced tumor growth in ASA-treated mice. Sixty SCID mice were injected intraperitoneally with $5 \times 10^{5} \mathrm{REN} /$ luc cells. After formation of tumor nodules detectable by IVIS imaging (4 days after cells injection), mice were weighed and randomly assigned to control (gavage of vehicle) and treatment (gavage of ASA at 25 or $50 \mathrm{mg} / \mathrm{kg}$ per day for the first 2 weeks and three times a week thereafter), groups of 20 animals each. (f) Tumor growth curves of the three animal groups up to 76 days. Measurement was halted thereafter as most mice in the control group had died. Based on a slope comparison test, treated animals showed a marked reduction in tumor growth $(t(443)=9.9, P<0.0001)$. (g) Kaplan-Meier survival plot of the three animal groups. Median survival was 76 days in the control group, 87.5 days in the ASA $25 \mathrm{mg} / \mathrm{kg}$ group and 91 days in the ASA $50 \mathrm{mg} / \mathrm{kg}$ group. The increase in survival of treated animals is statistically significant for both ASA -treated groups $\left(\chi^{2}(2)=38.0, P<0.0001\right.$, log-rank test)
} 
significant $\left(X^{2}(2)=38.0, P<0.0001\right.$, log-rank test) for both ASA- treated groups (Figure 1g). Overall, these data support the hypothesis that ASA/SA has therapeutic efficacy on established MM tumors.

Salicylates inhibit colony formation of MM cells. As MM growth relies on HMGB1 and HMGB1 is a critical factor for
MM pathogenesis, ${ }^{7}$ we hypothesized that the observed ASA antitumor effects on MM may be, at least in part, mediated via an HMGB1-dependent mechanism. Therefore, using a panel of three different patient-derived $\mathrm{MM}$ cell lines, REN, HMESO and PHI, we further analyzed whether ASA/SA could influence MM growth via targeting HMGB1 in vitro. All three cell lines secrete high amounts of HMGB1 a

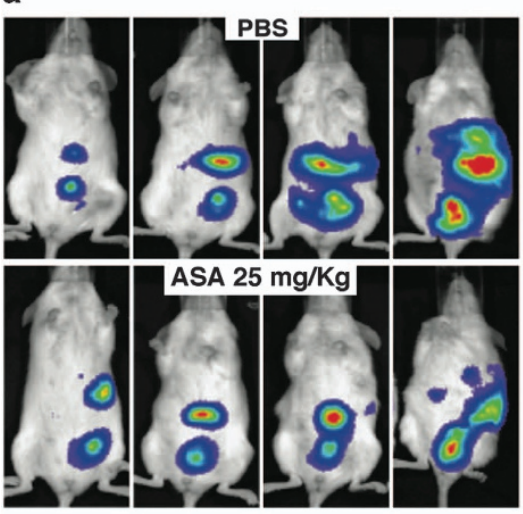

3 days 17 days 31 days 48 days

C

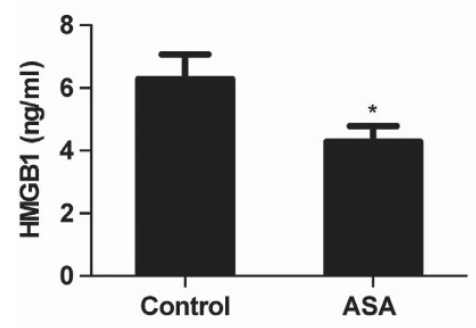

e

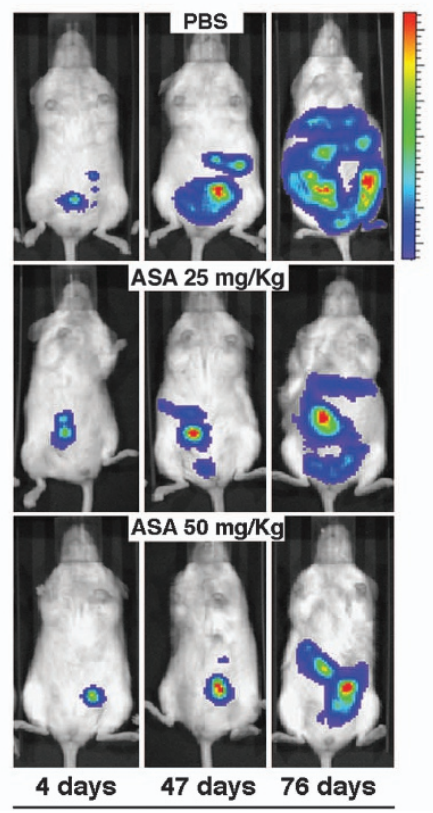

b

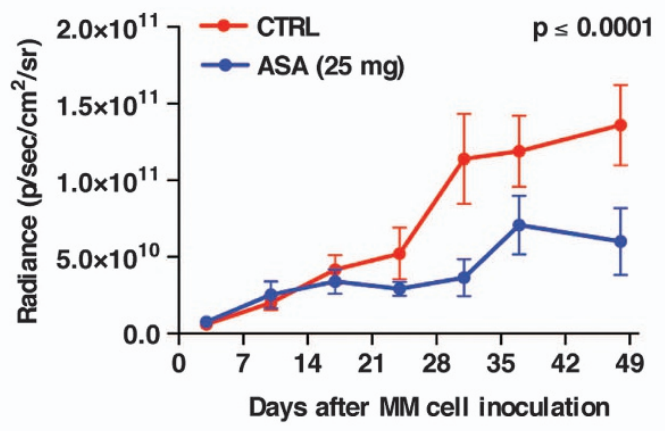

d

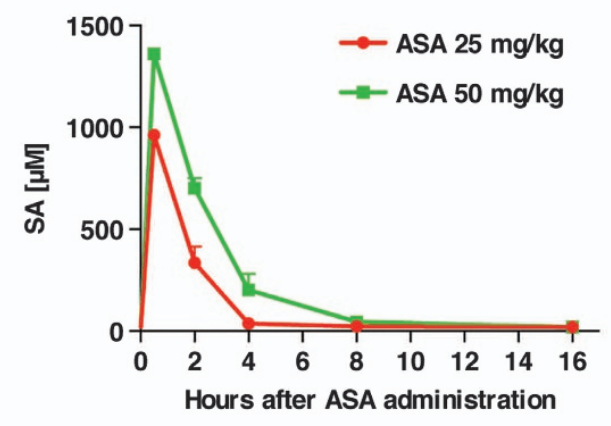

f

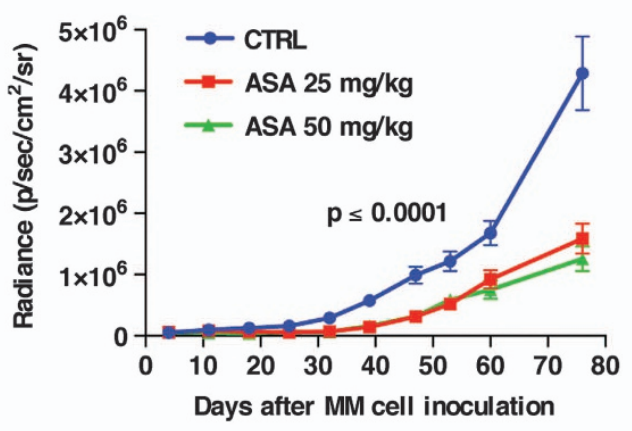

g

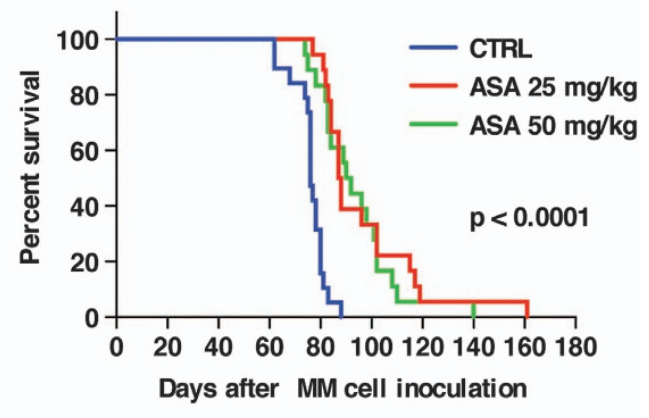


and are 'addicted' to HMGB1 for growth. ${ }^{7}$ The PPM-MILL cell line, which secretes low to undetectable amounts of HMGB1 and that does not require HMGB1 to grow, was used as a control. ${ }^{7}$

In vivo, ASA is rapidly metabolized to SA; however, the kinetics of this conversion in cell culture have not been elucidated. Our data show that $1 \mathrm{mM}$ of ASA (the highest concentration used in our in vitro experiments) was completely hydrolyzed to SA in $48 \mathrm{~h}$, with $46 \%$ and $76 \%$ of ASA converted into SA after 8 and $24 \mathrm{~h}$, respectively (Supplementary Figure S2). REN cells treated with therapeutic levels of salicylates showed no significant difference in viability compared with controls at $24 \mathrm{~h}$ (Supplementary Figure S3A) and $72 \mathrm{~h}$ (Supplementary Figure S3B), suggesting that ASA and SA are not directly cytotoxic.

To determine whether anchorage-independent growth of the HMGB1-secreting MM cell lines might be suppressed by ASA/SA, MM cell lines were cultured in 6-well plates coated with soft agar for 4 weeks. Fresh medium supplemented with $1 \%$ FBS and different doses of ASA/SA or vehicle was added every 2 days. Concentrations of ASA and SA as low as $100 \mu \mathrm{M}$ significantly inhibited the formation of colonies in soft agar of high HMGB1-secreting MM cells (Figures 2a-d), whereas no effects were observed on the anchorage-independent growth of the low HMGB1-secreting MM cell line, PPM-Mill (Figures $2 e$ and $\mathrm{f}$ ). These findings indicate that salicylates specifically suppressed anchorage-independent growth of MM cells that secrete high amounts of HMGB1 and require HMGB1 for their growth, supporting the hypothesis that ASA exerts antitumor/ MM activity through interfering with HMGB1 functions.

Salicylates inhibit HMGB1-dependent cell motility, migration, invasion and EMT signaling. To determine whether ASA inhibited HMGB1-dependent cell motility, migration and invasion, REN cells were treated with $100 \mathrm{ng} / \mathrm{ml}$ of reduced HMGB1, the isoform of HMGB1 that has chemoattractant activity, ${ }^{7,20}$ which induced cell motility, migration and Matrigel invasion (Figures $3 a-c)$. ASA and SA inhibited all HMGB1induced effects at concentrations as low as $0.1 \mu \mathrm{M} 48 \mathrm{~h}$ after administration (Figures $3 a-c$ ). In contrast, HMGB1 did not induce chemotactic migration of PPM-MILL cells (Supplementary Figure S4) and ASA/SA had no influence on PPM-MILL cells in any of the assays (Figures $2 e$ and $f$ ). To rule out the effects may be due to changes in cells viability, we examined the effect of ASA and SA on HMGB1-induced cell growth. We found that at $48 \mathrm{~h}, \mathrm{HMGB} 1$-induced REN cell growth was only slightly increased and that ASA and SA did not impact cell viability (Figure $3 d$ ). Therefore, the significant inhibitory effects of ASA and SA seen at $48 \mathrm{~h}$ on cell migration, motility and invasion were not caused by changes in cell proliferation. However, at $72 \mathrm{~h}, \mathrm{HMGB} 1$ induced significant cell growth above background, an additional mechanism by which HMGB1 promotes MM, and at this time point, ASA/SA inhibited HMGB1-induced cell growth (Figure 3e). Similar results were obtained with other HMGB1secreting MM cells (Supplementary Figure S5).

To investigate whether ASA and SA influences epithelialmesenchymal transition (EMT) in MM cells induced by HMGB1, we analyzed the expression of $\mathrm{N}$-cadherin and $\beta$-catenin in REN and PHI cells, upon treatment with ASA and SA in the presence of HMGB1 (Figure 4 and Supplementary Figure S6).
As shown in Figure 4, we observed that HMGB1 increased significantly the levels of both $\mathrm{N}$-cadherin and $\beta$-catenin and these effects were inhibited by ASA/SA, indicating that ASA and SA inhibited the expression of adhesion molecules and EMT signaling induced by HMGB1. We also found that HMGB1 induced $p$-AKT and that this activity was significantly reduced in the presence of ASA (Supplementary Figure S7). Inhibition of AKT activity may contribute to the overall inhibitory effect of ASA/SA on HMGB1-induced cell growth.

Overall, these results, together with the data from the colony formation assay (Figure 2), support the hypothesis that ASA/ SA specifically act on high HMGB1-secreting MM cells. These data demonstrate that at concentrations ranging from $0.1 \mu \mathrm{M}$ to $1 \mathrm{mM}$, which are the concentrations obtained in human serum, following ingestion of therapeutic levels of aspirin, salicylates effectively suppress the chemoattractant activities of HMGB1 in HMGB1-secreting MM cells and suppress the MM malignant phenotype induced by HMGB1.

Effect of salicylates on HMGB1-induced cell migration is independent of COX-2 and is not additive with the HMGB1 antagonist BoxA. Extracellular reduced HMGB1 acts as a chemoattractant and mediates migration of different cell types, including mouse embryonic fibroblasts, mononuclear cells and ovarian cancer cells. ${ }^{21-23}$ The primary action of ASA in mammals has been attributed to its effects on cyclooxygenase enzymes (COX), ${ }^{13,14}$ and COX-2 deficiency impairs cell adhesion and migration of macrophages. ${ }^{24}$ To test whether SA-mediated inhibition of chemotaxis was mediated via COX-2 rather than HMGB1, we used mouse embryonic fibroblasts (MEFs) with ablation of the gene coding for COX-2 (Pgts2) ${ }^{25}$ and performed the cell migration assay using both Ptgs2- / - MEFs and wild-type (WT) fibroblasts. Our data show that SA effectively inhibited HMGB1-induced fibroblasts migration in a dose-dependent manner, in both Ptgs2 - / - MEFs and WT fibroblasts, with an IC50 of $\sim 3-4 \mu \mathrm{M}$ (Figures $5 \mathrm{a}$ and b). In contrast, SA did not affect cell migration induced by the chemoattractant $N$-formylmethionyl-leucyl-phenylalanine (fMLP) (Figures $5 a$ and b). Thus, SA appears to inhibit specifically the chemoattractant activity of HMGB1, rather than suppress cell migration per se. To further investigate whether the antichemoattractant effects of salicylates on MM cells are through COX inhibition or not, we compared the effects of ASA to indomethacin, a nonselective inhibitor of COX, and we found that ASA, but not indomethacin, inhibited HMGB1-induced motility of MM cells (Supplementary Figure S8). In addition, we found that ASA and BoxA, a specific HMGB1 antagonist, ${ }^{26}$ did not have synergic or additive effects, as it would have been expected if they acted through different pathways (Figure $5 \mathrm{c}$ ). Taken together, these data support the hypothesis that the antichemoattractant effect of ASA is largely mediated via HMGB1dependent mechanisms and it is COX-2 independent.

Specific inhibition of HMGB1 significantly reduces tumor growth in vivo. Following the identification of a common pathway of action of ASA/SA and BoxA, we tested the efficacy of BoxA in vivo. Twenty SCID mice were injected intraperitoneally with $5 \times 10^{5}$ REN/luc cells. After formation of tumor nodules detectable by IVIS imaging (4 days after 

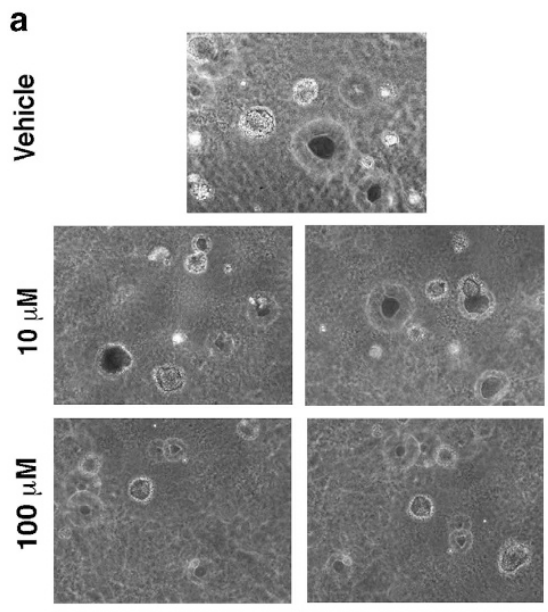

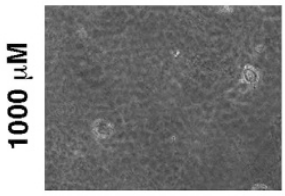

ASA

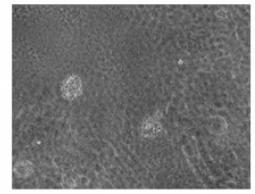

SA

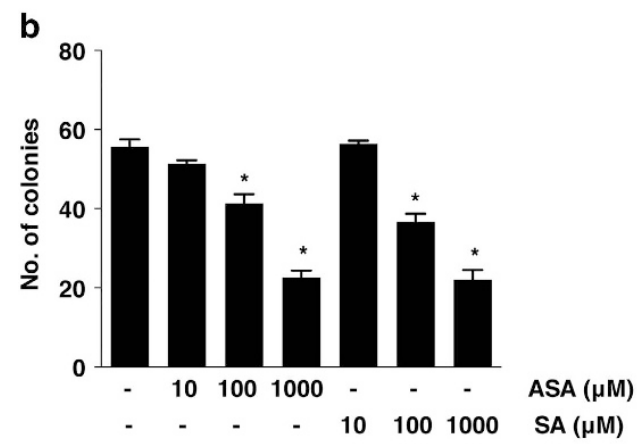

C
$\frac{0}{0}$
$\frac{0}{\frac{0}{0}}$

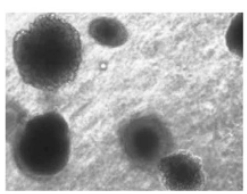

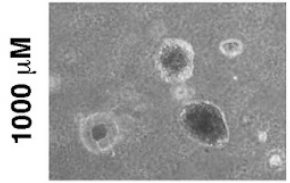

ASA

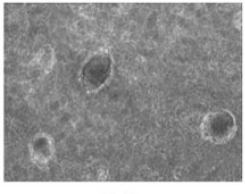

SA
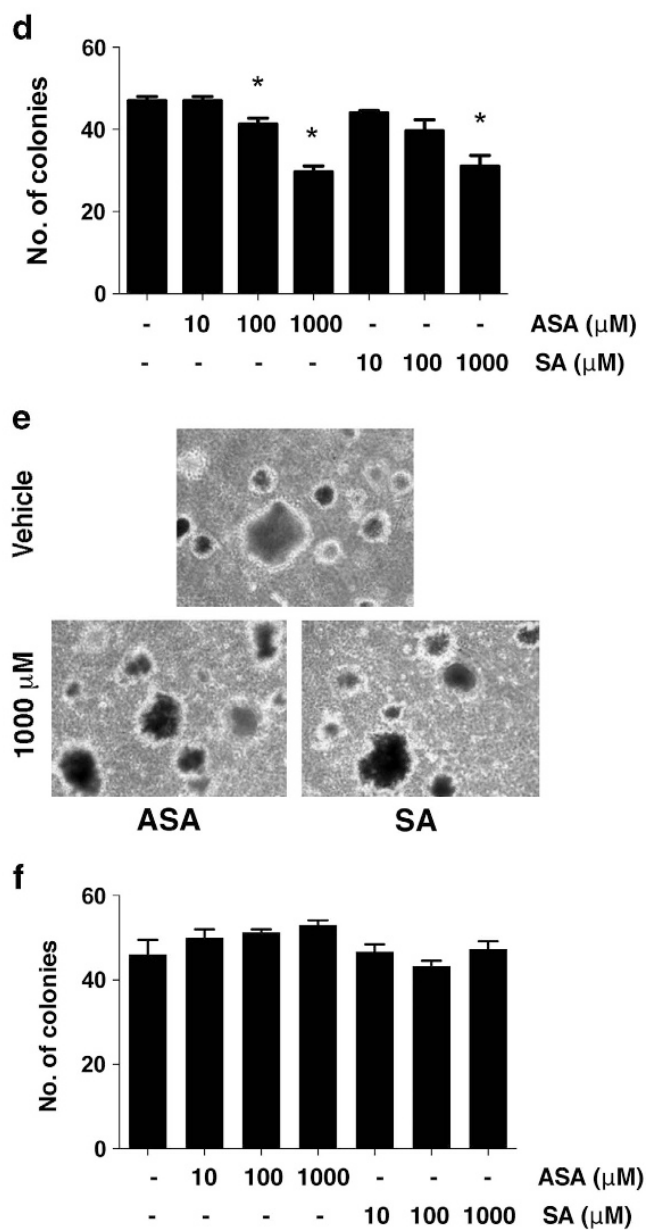

Figure 2 Salicylates inhibit anchorage-independent colony formation of high HMGB1-secreting REN and HMESO cells but not of low HMGB1-secreting PPM-MILL cells. Five thousand REN ( $\mathbf{a}$ and $\mathbf{b}$ ), HMESO ( $\mathbf{c}$ and $\mathbf{d}$ ) and PPM-MILL (e and $\mathbf{f}$ ) cells were seeded on soft agar-coated plates. Fresh medium (DMEM plus $1 \%$ FBS) supplemented with different concentrations of salicylates or vehicle control was added every 2 days for 4 weeks. Representative photographs of colonies (a, $\mathbf{c}$ and $\mathbf{e})$ and quantification of number of colonies (b, d and f). Cells were treated with vehicle or salicylates. For each well, all colonies larger than $0.1 \mathrm{~mm}$ in diameter were counted using the ImageJ software (NIH). In all panels, experiments were carried out in triplicate and repeated three times. ${ }^{*} P<0.05$

injection of REN/luc cells), mice were weighed and randomly assigned to control (PBS) and treatment $(400 \mu \mathrm{g}$ BoxA injection) groups of 10 animals each. Mice were injected intraperitoneally three times a week for a total of 10 weeks (12 mg BoxA/mouse in the treatment group). Based on a slope comparison test, tumors in BoxA-treated mice grew significantly slower than controls (Figure $6 a, t(146)=4.8$, $P<0.0001$ ), and these mice had a median survival of 142 days, compared with 76.5 days median survival in the control group in which the longest survival was 96 days (Figure 6b). Based on the log-rank test, this difference was statistically significant $\left(x^{2}(1)=18.4, P<0.0001\right)$. One animal in the BoxA-treated group survived 413 days when eventually it became ill and had to be killed. Necropsy revealed that this mouse died of a CD3+ T-cell lymphoma (Supplementary Figure S9), a tumor type that is frequent in SCID mice. Pathological and immunohistochemical studies revealed no evidence of residual human MM cells in this mouse. 
a

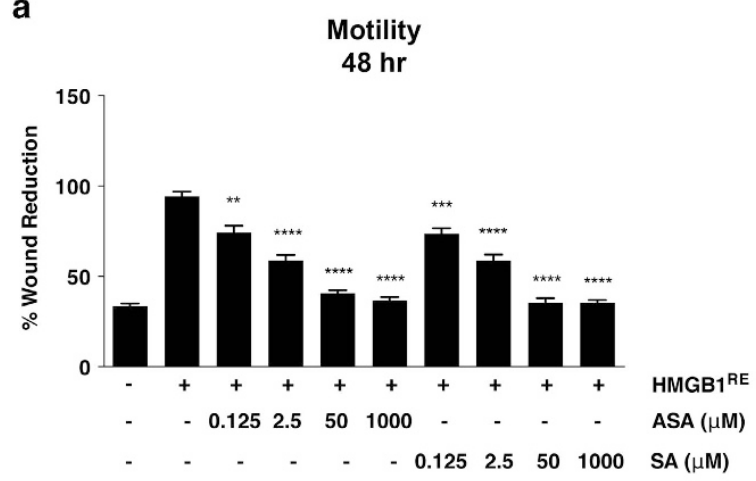

C

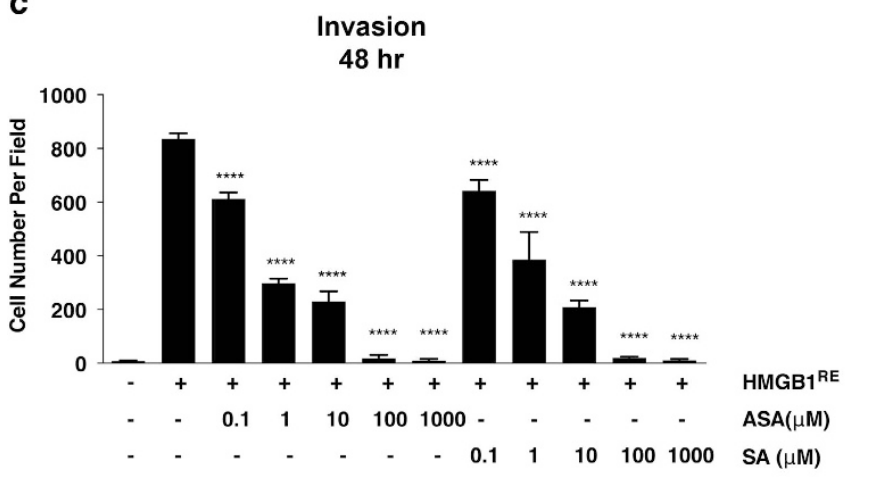

b

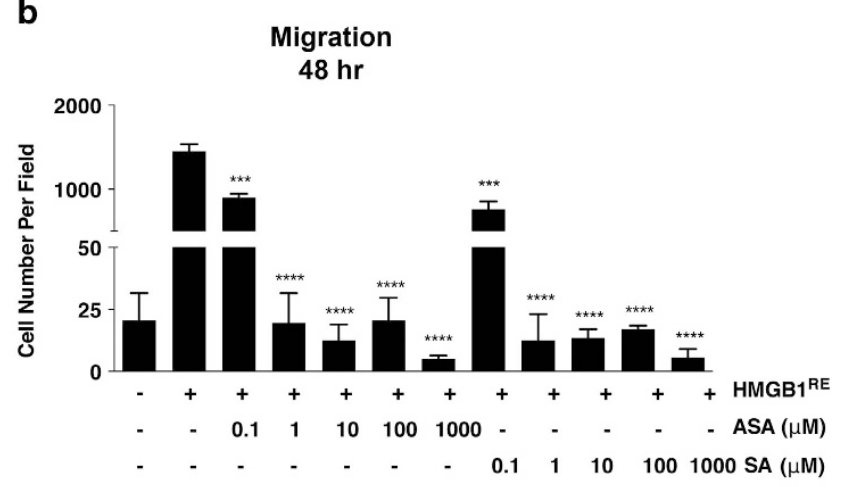

d

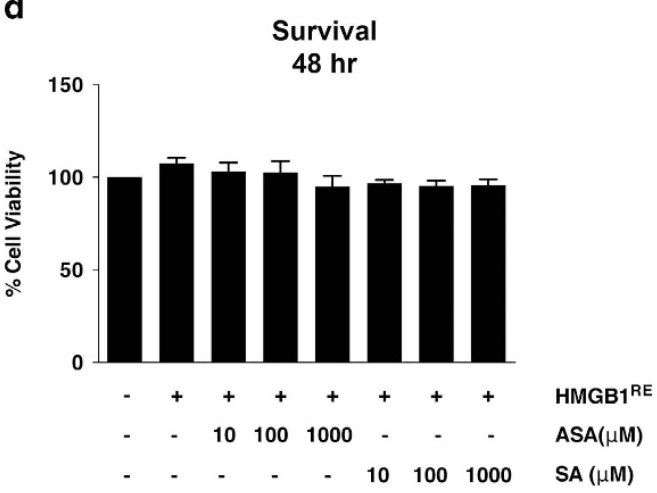

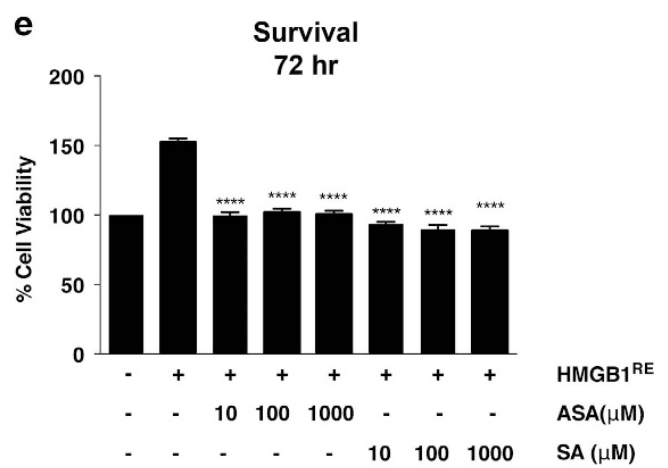

Figure 3 Salicylates inhibit MM cell migration, cell motility and invasion induced by HMGB1. (a) Quantification of wound healing assay of REN cells in the presence of HMGB1 $(100 \mathrm{ng} / \mathrm{ml})$ with or without different concentrations of ASA or SA after $48 \mathrm{~h}$. The percentage of wound reduction was analyzed using the ImageJ software (NIH). Experiments were carried out in triplicate. (b) Both ASA and SA inhibit HMGB1-induced MM cell migration. Quantification of REN cells migrating towards HMGB1 in the presence of different concentrations of ASA or SA. Bars represent mean values per field from three fields. (c) Both ASA and SA inhibit HMGB1-induced MM cell invasion. Quantification of Matrigel invasion of REN cells in the presence of HMGB1 and different concentrations of ASA or SA. Bars represent mean values per field from three fields. (d and $\mathbf{e})$ ASA and SA do not inhibit HMGB1-induced MM cell proliferation at $48 \mathrm{~h}$ (d), but significantly inhibit HMGB1-induced MM cell proliferation at $72 \mathrm{~h}(\mathrm{e})$. One thousand REN cells were treated with HMGB1 $(100 \mathrm{ng} / \mathrm{ml})$ in the presence or absence of different concentrations of ASA or SA. Cell metabolic activity was assessed by Alamar Blue assay after 48 and $72 \mathrm{~h}$. Effects of treatments were assessed by analysis of variance (ANOVA) with Bonferroni-corrected posttests. (Here we are comparing MM cells treated with HMGB1 in the presence or absence of ASA/SA.) ${ }^{* \star} P<0.01,{ }^{* * *} P<0.001$ and ${ }^{* * *} P<0.0001$

\section{Discussion}

We report that salicylates inhibit the activities of extracellular HMGB1 and that at least part of the anticancer effects of aspirin are due to inhibition of HMGB1's activities and are COX-2 independent.

The primary mechanism of action of aspirin in mammals has been attributed to the disruption of eicosanoid biosynthesis through the irreversible inhibition via acetylation of COX, thereby altering the levels of prostaglandins. ${ }^{13,14}$ Aspirin's protective effect against cancer has therefore been associated with the inhibition of COX. In supporting this, studies have shown that: (i) other NSAIDs that, similar to aspirin, inhibit COX activity, also reduce cancer risk, (ii) COX-2 is overexpressed in many tumors, and (iii) Ptgs2 (Cox-2)-null mice have much reduced number of precancerous colon polyps. ${ }^{27}$ In contrast, other studies challenge the hypothesis that COX inhibition is responsible for the anticancer effects of aspirin and other NSAIDs, ${ }^{28}$ because: (i) inhibition of cancer cell growth by NSAIDs cannot be reversed by addition of prostaglandins, (ii) genetic suppression of Cox-1 and/or 

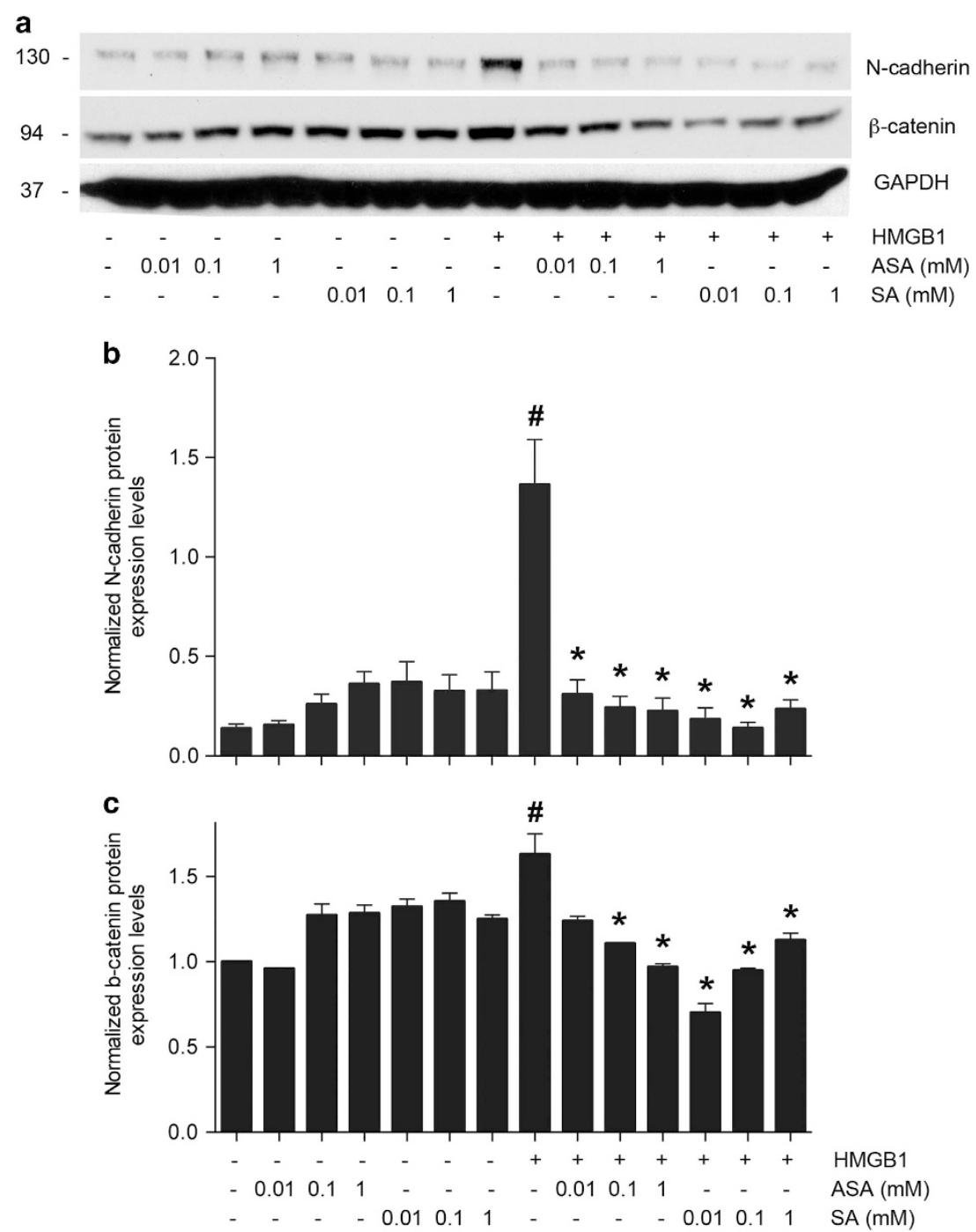

Figure 4 Salicylates inhibit N-cadherin and $\beta$-catenin expression induced by HMGB1. (a) Representative western blots show N-cadherin and $\beta$-catenin expression in REN MM cells treated with HMGB1 in the presence or absence of different concentrations of ASA or SA. (b and c) The expression of N-cadherin (b) and $\beta$-catenin (c) relative to glyceraldehyde 3-phosphate dehydrogenase (GAPDH) levels was evaluated as band density using the ImageJ software (NIH). "Significantly different compared with MM cells not treated with HMGB1. *Significantly different compared with MM cells treated with HMGB1 in the absence of salicylates $(P<0.05)$

Cox-2 expression often does not alter sensitivity to NSAIDs, and (iii) some derivatives, metabolites or enantiomers of several NSAIDs retain anticancer activity despite having lost their ability to inhibit COX-1/2. Taken together, these studies argue that mechanism(s) independent of inhibition of the COX activity of COX-1/2 are, at least partially, responsible for the anticancer activity of aspirin and other NSAIDs, a conclusion also reached by others. ${ }^{29}$

In the present study, we examined whether aspirin and its metabolite, SA, exert anticancer activity against MM by inhibiting the biological effects of HMGB1 at physiologically relevant concentrations. We found that ASA significantly inhibited MM growth in a xenograft model, a result that was reproduced using gavage feeding in two independent experiments. The mean survival of mice treated with 25 or $50 \mathrm{mg} / \mathrm{kg}$ ASA were significantly higher as compared with untreated control mice (Figure 1). Therapeutic levels of ASA and SA suppressed the migration, invasion, wound healing, EMT signaling and anchorage-independent colony formation of HMGB1-secreting MM cells but not those of MM cells, which secrete low to undetectable amounts of HMGB1, suggesting that the antitumor activity of ASA/SA was related to HMGB1 (Figures 2-4). Moreover, SA inhibited HMGB1-induced cell migration in MEFs in which the gene coding for COX-2 (Pgts2) had been genetically ablated indicating that this effect is COX-2 independent (Figures $5 \mathrm{a}$ and $\mathrm{b}$ ). These findings support the interpretation that the observed biological/ antitumor effects were a direct consequence of SA-mediated inhibition of HMGB1 activities.

As aspirin, in addition to inhibiting HMGB1, has other activities, we used BoxA, a specific HMGB1 antagonist ${ }^{26}$ to determine whether specific inhibition of HMGB1 function mimicked the effects of aspirin. We tested whether HMGB1 inhibition alone was sufficient to account for the antichemoattractant activity and reduced tumor growth or whether other aspirin activities were also required. In vitro, the 

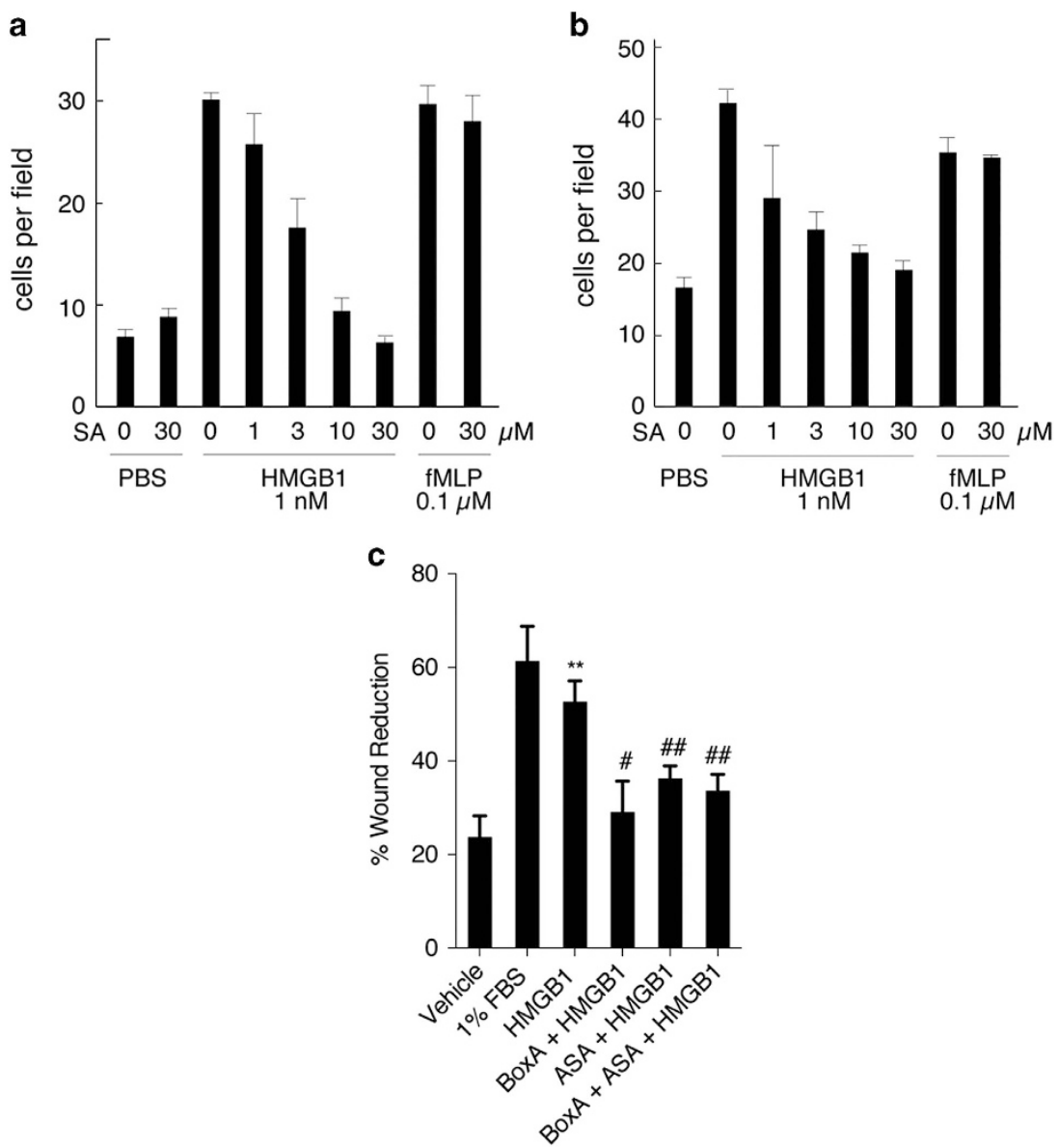

Figure 5 Effect of salicylates on HMGB1-induced cell migration is COX-2 independent and is not additive with BoxA. (a and b) SA suppresses HMGB1's chemoattractant activity on mouse 3 T3 fibroblasts (a) and MEFs knock out for COX-2 (Ptgs2 - / - ) (b). Cell migration was performed in Boyden chambers $3 \mathrm{~h}$ after stimulation with $1 \mathrm{nM}$ reduced HMGB1, $0.1 \mu \mathrm{M}$ fMLP or buffer (phosphate-buffered saline (PBS)). Bars represent the mean of triplicate samples $(P<0.001$ in analysis of variance (ANOVA)). (c) Quantification of wound healing assay of PHI cells in the presence of HMGB1 and ASA or BoxA alone or in combination after $48 \mathrm{~h}$. The percentage of wound reduction was analyzed using the ImageJ software $(\mathrm{NIH})$. Experiments were carried out in triplicate. ${ }^{* \star} P<0.002$, HMGB1-treated cells compared with vehicle. ${ }^{\#} P=0.01$ and ${ }^{\# \#} P<0.005$, MM cells treated with HMGB1 in the presence of BoXA, ASA or BoXA+ASA compared with cells treated with HMGB1 alone
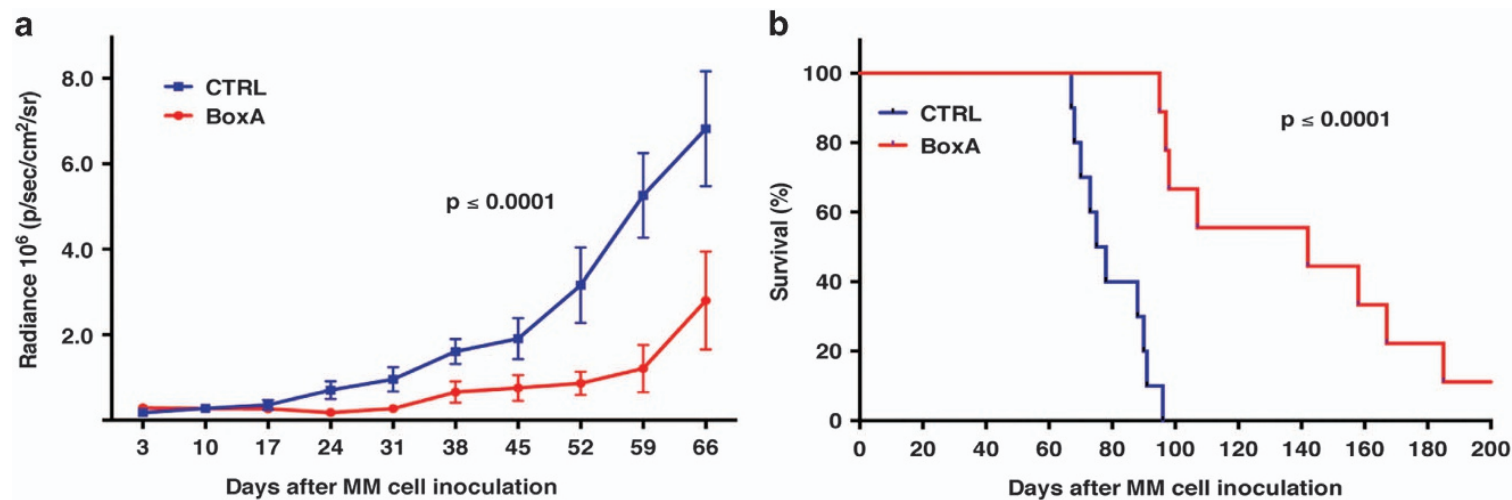

Figure 6 BoxA significantly reduces tumor growth in an MM xenograft model. (a) Tumor growth curves of BoxA-treated mice and controls. Based on a slope comparison test, tumors in BoxA-treated mice grew significantly slower than controls $(t(146)=4.8, P<0.0001)$. (b) Survival curve of the two groups. BoxA-treated mice had a median survival of 142 days, compared with 76.5 days median survival in the control group in which the longest survival was 96 days. Based on the log-rank test, this difference was statistically significant $\left(\chi^{2}(1)=18.4, P<0.0001\right)$ 
combination of ASA and BoxA did not increase their antichemoattractant activity (Figure 4c). The data are consistent with the two agents being in the same pathway. In vivo, BoxA administration produced similar antitumor effects as observed with aspirin, without causing the well-known side effects of aspirin, that is, Gl bleeding. Median survival in control mice was 76.5 days and maximum survival was 96 days, whereas median survival of BoxA-treated mice was 142 days (Figures $6 a$ and b). One of the BoxA-treated mice survived 413 days. This mouse eventually died of a mouse T-cell lymphoma and human MM cells could no longer be detected in it (Supplementary Figure S8). In summary, BoxA was more effective than ASA in suppressing MM growth and extending survival, and mice treated with BoxA did not appear to suffer any side effects.

Although BoxA is not yet available for clinical use, aspirin is. The beneficial effects of aspirin and BoxA detected in our study were observed treating animals during the early stages of tumor growth. Our experiments were not designed to address the possible beneficial effects of aspirin and BoxA on symptomatic MM with large tumor masses. Therefore, similar to what has been proposed for colon cancer, ${ }^{14}$ we propose that in human $\mathrm{MM}$ the beneficial effects of aspirin and BoxA may be better achieved during the early phases of tumor growth and/or in a preventive/early stage setting. Thus, aspirin administration to individuals at high risk of developing $\mathrm{MM}$, such as those with a history of asbestos and or erionite exposure or germline BAP1 mutation carriers, ${ }^{1,2}$ may prevent or delay the growth of $\mathrm{MM}$, possibly increasing life expectancy and also increasing opportunities for early MM detection, which is associated with a prolonged life expectancy. ${ }^{1}$ In this regard, promising new $\mathrm{MM}$ biomarkers are being developed to increase opportunities for early MM detection in cohorts at high risk for $\mathrm{MM}^{3,30}$

Our data present a compelling argument that at least some of the so far elusive antitumor activity of aspirin is mediated through inhibition of HMGB1 activity. Future studies shall address the precise mechanism by which ASA inhibits HMGB1. In summary, we propose a novel mechanism by which aspirin may exert its antitumorigenic properties (i.e., HMGB1 inhibition) while remaining consistent with its well-described anti-inflammatory properties. Indeed, by identifying HMGB1 as a potential target of salicylates in our experimental MM system, we provide a proof-of-concept of a novel therapeutic mechanism that is responsible for aspirin's anticancer effects. Our results are of relevance to $\mathrm{MM}$, and also to other inflammation-related malignancies, such as melanoma, breast, GI, prostate, and pancreatic cancers, whose growth and development appear also supported by high levels of HMGB1.,8

\section{Materials and Methods}

Study design. This study objective was to investigate the HMGB1-mediated antitumorigenic effects of salicylates. To this aim, we designed in vitro and in vivo assays using high and low HMGB1-secreting MM cell lines, which exhibit different HMGB1 dependence for cell growth. Sample selection for in vitro studies was based on availability of high and low HMGB1-secreting MM cell lines. Sample numbers and experimental replicates for each experiment are indicated in the figure legends. MM sample selection for our in vivo orthotopic xenograft mouse model was based on high HMGB1 secretion levels and on robust intraperitoneally grafting in SCID mice. Sample size, randomization and in vivo study end points are described in the 'Animal Studies' Section in the Materials and Methods.
Cell cultures and reagents. The MM cell lines PPM-MILL, PHI (originally denominated as HP3; Pass et $a / .^{31}$ ), and HMESO were established from surgically resected human MM specimens and characterized for their mesothelial origin by Drs. Harvey Pass and John Minna at the National Cancer Institute (NCl, Bethesda, MD, USA). ${ }^{7}$ The MM cell line REN was provided by Dr. Steven Albelda (University of Pennsylvania, Philadelphia, PA, USA). This line was originally derived from an explant of an epithelial mesothelioma. MM cell line characterization is performed routinely in our lab by immunostaining using specific antibodies against mesothelial markers, including WT-1, calretinin and pancytokeratin. All MM cell lines routinely tested negative for mycoplasma contamination. All cell lines were cultured in Dulbecco's modified Eagle's medium (DMEM; Gibco, Grand Island, NY, USA), supplemented with $10 \% \mathrm{FBS}$ at $37^{\circ} \mathrm{C}$ in a $5 \% \mathrm{CO}_{2}$ atmosphere. REN/luc cells expressing luciferase were generated by our lab as described previously. ${ }^{7}$ MEFs were derived from Ptgs2 - / - E16 mouse embryos: Ptgs2+ / - mice were purchased from Taconic Biosciences (Germantown, NY, USA) and mated to obtain Ptgs2 - / - embryos; embryos were genotyped. ${ }^{25}$ The 3 T3 cells were purchased from ATCC (Manassas, VA, USA). Full-length, lipopolysaccharide-free purified reduced HMGB1 and BoxA were obtained from HMGBiotech (Milan, Italy). ASA, SA and indomethacin were purchased from Sigma-Aldrich (St. Louis, MO, USA) and were dissolved in ethanol. fMLP was obtained from Sigma-Aldrich. Salicylates ELISA Kit used for SA measurement was purchased from Neogen (Lansing, MI, USA). HMGB1 ELISA kit was purchased from IBL International (Hamburg, Germany).

Cell viability assay. REN cells were plated in a 96-well plate $\left(1 \times 10^{3}\right.$ per well), starved overnight and treated with HMGB1 $(100 \mathrm{ng} / \mathrm{ml})$ with or without various concentrations of ASA/SA. Cell viability was assessed using the Alamar Blue (AbD Serotec (Raleigh, NC, USA)) assay according to the manufacturer's instructions 48 and $72 \mathrm{~h}$ after treatment.

Motility assay. MM cells were grown in 6-well plates to $80-90 \%$ confluence in medium supplemented with $10 \%$ FBS. The cell monolayer was then scratched with a P200 tip, serum-free medium supplemented with HMGB1 $(100 \mathrm{ng} / \mathrm{ml})$ and different concentrations of ASA or SA (ranging from $0.1 \mu \mathrm{M}$ to $1 \mathrm{mM}$ ) were added, and cells were allowed to close the wound for $48 \mathrm{~h}$. Migration distance was photographed and measured at zero time and after $48 \mathrm{~h}$ using the ImageJ software (NIH, Bethesda, MD, USA).

Migration and invasion assays. The in vitro cell migration and invasion assays were carried out using Costar Transwell-permeable polycarbonate supports $(8.0 \mu \mathrm{m}$ pores) in 24-well plates (Corning Inc., New York, NY, USA). A total of $1 \times 10^{5} \mathrm{MM}$ cells were seeded in the insert in serum-free medium. For the invasion assays, the upper compartment of the support was coated with Matrigel (BD, San Jose, CA, USA). Experiments were performed in triplicate. MM cells were seeded on the top compartment of a Boyden chamber. The lower chamber was filled with serum-free medium supplemented with HMGB1 $(100 \mathrm{ng} / \mathrm{ml})$ and with or without different concentrations of either ASA or SA (ranging from $0.1 \mu \mathrm{M}$ to $1 \mathrm{mM}$ ), and cells were allowed to migrate or invade for either 3 (MEF and 3T3) or $48 \mathrm{~h}$ (MM cell lines). The invaded/migrated cells were quantified per field of view using the ImageJ software $(\mathrm{NIH})$ and statistically analyzed.

Western blotting. Total cell protein extracts were prepared using lysis buffer (Sigma-Aldrich). Fifty micrograms of protein were used for each sample. The proteins were separated on a $10 \%$ polyacrylamide gel and transferred to polyvinylidene difluoride membranes (EMD Millipore, Darmstadt, Germany). The membranes were blocked in Tris-buffered saline containing 0.05\% Tween-20 (TBST) and $5 \%$ bovine serum albumin at $4{ }^{\circ} \mathrm{C}$ overnight before incubation with specific primary and secondary antibodies. The antibodies used were $\mathrm{N}$-cadherin, $\beta$-catenin (Santa Cruz Biotechnology, Dallas, TX, USA) and GAPDH (EMD Millipore). The relative density of western blot bands was evaluated by ImageJ software $(\mathrm{NIH})$.

Soft agar assay. MM cells were incubated with different concentrations of ASA or SA (ranging from $0.1 \mu \mathrm{M}$ to $1 \mathrm{mM}$ ) and the anchorage-independent cell proliferation was assayed as described previously. ${ }^{7}$ Briefly, the cells $\left(5 \times 10^{3}\right)$ were mixed with an equal volume of $0.6 \%$ agar in DMEM $10 \%$ FBS and placed on top of a 6-well plate precoated with $1.2 \%$ agar in DMEM plus $10 \%$ FBS. Cells were incubated at $37^{\circ} \mathrm{C}$ with $5 \% \mathrm{CO}_{2}$ and fresh medium (DMEM plus $1 \% \mathrm{FBS}$ ) supplemented with different concentrations of ASA or SA (ranging from $0.1 \mu \mathrm{M}$ to $1 \mathrm{mM}$ ) was added every 2 days. After 4 weeks of culture, the number and size of the 
colonies formed in each treatment were evaluated. For each well, all colonies larger than $0.1 \mathrm{~mm}$ in diameter were counted using the ImageJ software.

Animal studies. SCID (NOD.CB17-SCID) female mice aged 6 to 8 weeks (Jackson Laboratories, Bar Harbor, ME) were housed and handled under aseptic conditions, in accordance with the University of Hawaii's Institutional Animal Care and Use Committee (IACUC) guidelines. An orthotopic mouse model of MM was established by intraperitoneal injection of $5 \times 10^{5}$ REN/luc cells suspended in $500 \mu \mathrm{l}$ of PBS. Cells were visualized by luminescence after D-luciferin injection $(150 \mathrm{mg} / \mathrm{kg})$ using the In Vivo Imaging System (IVIS; Xenogen Corp., Alameda, CA, USA), with regions of interest quantified as total photon counts by Living Image software (Xenogen Corp.). Mice were then weighed and randomly assigned to control and treatment groups. Treatments were ASA, BoxA or vehicle solutions. ASA was first dissolved in dimethyl sulfoxide, and then diluted to $2.5 \mathrm{mg} / \mathrm{ml}$ with $0.5 \%$ carboxymethylcellulose sodium salt (Sigma-Aldrich). ${ }^{19}$ BoxA $(400 \mu \mathrm{g})$ was diluted in $200 \mu$ l of PBS. Control (vehicle) solutions were DMSO in $0.5 \%$ carboxymethylcellulose or PBS for ASA and BoxA, respectively. ASA treatments were administrated via oral gavage, whereas BoxA was administered via intraperitoneal injection. Throughout treatment, tumor dimension was measured every seventh day as average radiance (photons $/ \mathrm{s} / \mathrm{cm}^{2} / \mathrm{sr}$ ) by IVIS. Primary end points were tumor size and survival. The animals were killed when declared 'ill' by the vivarium veterinary team (i.e., because of tumor masses $>2 \mathrm{~cm}$, dyspnea, ascites, lethargy, and so on). Animals were necropsied and all abdominal organs were analyzed histologically. The cause of death for all the mice used in the xenograft model was intestinal occlusion caused by tumor nodules, except for one mouse in the BoxA-treated group, which died accidently during a blood draw to measure HMGB1 serum levels. In the first ASA mouse experiment, $14 \mathrm{MM}$-xenotransplanted SCID mice were randomized into two groups of seven animals each, receiving ASA $25 \mathrm{mg} / \mathrm{kg}$ or vehicle daily via oral gavage. Mice were treated for 48 days, and during the course of the experiment, ASA-treated animals experienced weight loss and died of Gl bleeding. In the second ASA mouse experiment, $60 \mathrm{MM}$-xenografted SCID mice were randomized into three groups of 20 animals each. Treatment groups received ASA 25 or $50 \mathrm{mg} /$ $\mathrm{kg}$, daily for the first 2 weeks, and then three times a week thereafter. During the course of the experiment, there was no difference in body weight between the control and treatment groups, and no evidence of Gl bleeding. In the BoxA in vivo experiment, $20 \mathrm{MM}$-xenografted SCID mice were randomized into two groups (control and treatment) of 10 animals each. Mice were treated intraperitoneal with either $400 \mu \mathrm{g}$ BoxA or vehicle (PBS) three times per week for 10 weeks (12 mg total BoxA/mouse). There was no difference in body weight between the control and treatment groups during the course of the experiment.

Immunohistochemistry. Immunohistochemistry was performed with antiCD3 antibodies (Abcam, San Francisco, CA, USA; rabbit polyclonal). Vectastain Elite ABC Kit (rabbit IgG; Vector Labs, Burlingame, CA, USA) was used according to the manufacturer's instructions. The staining was analyzed blindly by two boardcertified pathologists (AP and MC).

Statistical analysis. Statistical analysis is described in the Result section and in the Figure legends. Unless otherwise specified, statistical differences were evaluated by unpaired Student's $t$-test and considered significant at $P<0.05$.

\section{Conflict of Interest}

The University of Hawaii has filed for patents on HMGB1 and mesothelioma, on which HY, MC, MEB, and HIP are inventors. MC provides consultation for mesothelioma expertise and diagnosis. MEB is founder and part owner of HMGBiotech.

Acknowledgements. We thank Dr. Shumin Zhang, Harvard School of Public Health, for information and discussion about the Physician's Health Study. We are grateful to Drs. Marcus Tius, James Turkson, Joe Ramos and David C Ward for critical reading of this manuscript and Simone Patergnani for technical advice. This work was supported by the NCl-R01 CA160715, DOD CA120355 and The Riviera United 4-a Cure (to HY), and by NCI P01 CA114047 and NCI P30 CA071789 (to MC); by the V-Foundation (to $\mathrm{MC}$ and $\mathrm{HY}$ ), by the University of Hawai'i Foundation, which received donations to support mesothelioma research from Honeywell International Inc. (to MC); by Ricerca Finalizzata from the Italian Ministry of Health (to MEB) and by the Associazione Italiana Ricerca sul Cancro (IG-10411 to MEB, IG-14442 to PP and MFAG-13521 to CG).

\section{Author contributions}

HYand MC designed and directed the study. LP, AN, CG, SJ, A Preti, CJJ, FDM, EGF, $\mathrm{DL}$ and MT performed experiments. IP performed statistical analysis. AP and MC performed and reviewed pathology, histology and immunohistochemistry. HY, MC, SK and SP reviewed experimental results, performed data analysis and wrote the manuscript. MB, SK, GG, HIP, PP and SP critically reviewed the results. MEB designed and directed some of the experiments and contributed to the writing of the manuscript.

1. Carbone M, Ly BH, Dodson RF, Pagano I, Morris PT, Dogan UA, et al. Malignant mesothelioma: facts, myths, and hypotheses. J Cell Physiol 2012; 227: 44-58.

2. Carbone M, Yang H, Pass HI, Krausz T, Testa JR, Gaudino G. BAP1 and cancer. Nat Rev Cancer 2013; 13: 153-159.

3. Carbone M, Yang H. Molecular pathways: targeting mechanisms of asbestos and erionite carcinogenesis in mesothelioma. Clin Cancer Res 2012; 18: 598-604.

4. Scaffidi $P$, Misteli T, Bianchi ME. Release of chromatin protein HMGB1 by necrotic cells triggers inflammation. Nature 2002; 418: 191-195.

5. Yang H, Rivera Z, Jube S, Nasu M, Bertino P, Goparaju C, et al. Programmed necrosis induced by asbestos in human mesothelial cells causes high-mobility group box 1 protein release and resultant inflammation. Proc Natl Acad Sci USA 2010; 107: 12611-12616.

6. Gardella S, Andrei C, Ferrera D, Lotti LV, Torrisi MR, Bianchi ME et al. The nuclear protein HMGB1 is secreted by monocytes via a non-classical, vesicle-mediated secretory pathway. EMBO Rep 2002; 3: 995-1001.

7. Jube S, Rivera ZS, Bianchi ME, Powers A, Wang E, Pagano I et al. Cancer cell secretion of the DAMP protein HMGB1 supports progression in malignant mesothelioma. Cancer Res 2012; 72: 3290-3301.

8. Ellerman JE, Brown CK, de Vera M, Zeh HJ, Billiar T, Rubartelli A, et al. Masquerader: high mobility group box-1 and cancer. Clin Cancer Res 2007; 13: 2836-2848.

9. Bald T, Quast T, Landsberg J, Rogava M, Glodde N, Lopez-Ramos D et al. Ultraviolet-radiation-induced inflammation promotes angiotropism and metastasis in melanoma. Nature 2014; 507: 109-113.

10. Tabata C, Kanemura S, Tabata R, Masachika E, Shibata E, Otsuki TI, et al. Serum HMGB1 as a diagnostic marker for malignant peritoneal mesothelioma. J Clin Gastroenterol 2013; 47 684-688.

11. Chung HW, Lim JB, Jang S, Lee KJ, Park KH, Song SY. Serum high mobility group box-1 is a powerful diagnostic and prognostic biomarker for pancreatic ductal adenocarcinoma. Cancer Sci 2012; 103: 1714-1721.

12. Lee $\mathrm{H}$, Song M, Shin N, Shin CH, Min BS, Kim HS et al. Diagnostic significance of serum HMGB1 in colorectal carcinomas. PLoS One 2012; 7: e34318.

13. Weissmann G. Aspirin. Scientific Am 1991; 264: 84-90.

14. Ulrich CM, Bigler J, Potter JD. Non-steroidal anti-inflammatory drugs for cancer prevention: promise, perils and pharmacogenetics. Nat Rev Cancer 2006; 6: 130-140.

15. Rothwell PM, Wilson M, Price JF, Belch JF, Meade TW, Mehta Z. Effect of daily aspirin on risk of cancer metastasis: a study of incident cancers during randomised controlled trials. Lancet 2012; 379: 1591-1601.

16. Benedek IH, Joshi AS, Pieniaszek HJ, King SY, Kornhauser DM. Variability in the pharmacokinetics and pharmacodynamics of low dose aspirin in healthy male volunteers. J Clin Pharmacol 1995; 35: 1181-1186.

17. Cerletti C, Bonati M, del Maschio A, Galletti F, Dejana E, Tognoni G et al. Plasma levels of salicylate and aspirin in healthy volunteers: relevance to drug interaction on platelet function. J Lab Clin Med 1984; 103: 869-877.

18. Steering Committee of the Physicians' Health Study Research Group. Final report on the aspirin component of the ongoing Physicians' Health Study. N Engl J Med 1989; 321: $129-135$.

19. Reuter BK, Zhang XJ, Miller MJ. Therapeutic utility of aspirin in the ApcMin/+ murine model of colon carcinogenesis. BMC Cancer 2002; 2: 19

20. Antoine DJ, Harris HE, Andersson U, Tracey KJ, Bianchi ME. A systematic nomenclature for the redox states of high mobility group box (HMGB) proteins. Mol Med 2014; 20: 135-137.

21. Schiraldi M, Raucci A, Munoz LM, Livoti E, Celona B, Venereau E et al. HMGB1 promotes recruitment of inflammatory cells to damaged tissues by forming a complex with CXCL12 and signaling via CXCR4. J Exp Med 2012; 209: 551-563.

22. Venereau $E$, Casalgrandi M, Schiraldi M, Antoine DJ, Cattaneo A, De Marchis $F$ et al. Mutually exclusive redox forms of HMGB1 promote cell recruitment or proinflammatory cytokine release. J Exp Med 2012; 209: 1519-1528.

23. Chen J, Liu X, Zhang J, Zhao Y. Targeting HMGB1 inhibits ovarian cancer growth and metastasis by lentivirus-mediated RNA interference. J Cell Physiol 2012; 227: 3629-3638.

24. Diaz-Munoz MD, Osma-Garcia IC, Iniguez MA, Fresno M. Cyclooxygenase-2 deficiency in macrophages leads to defective p110gamma PI3K signaling and impairs cell adhesion and migration. J Immunol 2013; 191: 395-406.

25. Morham SG, Langenbach R, Loftin CD, Tiano HF, Vouloumanos N, Jennette JC et al. Prostaglandin synthase 2 gene disruption causes severe renal pathology in the mouse. Cell 1995; 83: 473-482.

26. Yang H, Ochani M, Li J, Qiang X, Tanovic M, Harris HE et al. Reversing established sepsis with antagonists of endogenous high-mobility group box 1. Proc Natl Acad Sci USA 2004; 101: 296-301. 
27. Brown JR, DuBois RN. COX-2: a molecular target for colorectal cancer prevention. J Clin Oncol 2005; 23: 2840-2855.

28. Gurpinar E, Grizzle WE, Piazza GA. COX-independent mechanisms of cancer chemoprevention by anti-Inflammatory drugs. Front Oncol 2013; 3: 181.

29. Tinsley HN, Grizzle WE, Abadi A, Keeton A, Zhu B, Xi Y, et al. New NSAID targets and derivatives for colorectal cancer chemoprevention. Recent Results Cancer Res 2013; 191: 105-120.

30. Carbone M, Ferris LK, Baumann F, Napolitano A, Lum CA, Flores EG, et al. BAP1 cancer syndrome: malignant mesothelioma, uveal and cutaneous melanoma, and MBAITs. J Trans Med 2012; 10: 179.

31. Pass HI, Stevens EJ, Oie H, Tsokos MG, Abati AD, Fetsch PA et al. Characteristics of nine newly derived mesothelioma cell lines. Ann Thorac Surg 1995; 59: 835-844. (c) (i) Cell Death and Disease is an open-access journal published by Nature Publishing Group. This work is licensed under a Creative Commons Attribution 4.0 International License. The images or other third party material in this article are included in the article's Creative Commons license, unless indicated otherwise in the credit line; if the material is not included under the Creative Commons license, users will need to obtain permission from the license holder to reproduce the material. To view a copy of this license, visit http://creativecommons.org/licenses/by/4.0/

Supplementary Information accompanies this paper on Cell Death and Disease website (http://www.nature.com/cddis) 